\title{
Dietary habits in Greek children with functional constipation based on Rome III criteria: a school-based, cross-sectional multivariate analysis
}

\author{
Giorgos L. Chouliaras ${ }^{a}$, Panagiotis Krepis ${ }^{a}$, Ilias Bouzios ${ }^{b}$, Aglaia Zellos $^{b}$, George Chrousos ${ }^{b}$, \\ Eleftheria Roma-Giannikoub
}

"P. \& Ag. Kyriakou” Children’s Hospital; Aghia Sophia Children’s Hospital, Athens, Greece

Abstract

\begin{abstract}
Background Functional constipation (FC) is the most common gastrointestinal disorder of childhood and has a multifactorial etiology. We aimed to assess dietary habits in Greek children with FC compared to the general population (control group, CG).
\end{abstract}
Methods This was a subgroup analysis of a school-based, cross-sectional study carried out in children 6-18 years of age, between January and June 2014, using the Rome III criteria for the diagnosis of FC. Dietary parameters, as well as socioeconomic and demographic data and their association with the likelihood of FC, were analyzed through multivariate logistic regression analysis and expressed as odds ratios (OR).

Results A total of 1439 children (1218 CG, 221 FC) were included in the analysis. The final model showed that consumption of was the only dietary parameter significantly related to FC; higher frequency of consumption was inversely related to the likelihood of FC (OR: 0.98, 95\% CI: 0.96, $0.99, \mathrm{P}=0.048)$. Significant socioeconomic confounders with a positive association with FC were: parental educational level, victimization, physical activity and number of adults at home.

Conclusion Increased frequency of fiber consumption is significantly associated with higher odds of FC irrespective of socioeconomic background and lifestyle parameters. Interventional studies are required to validate these cross-sectional observations.

Keywords Constipation, diet, population study, children, ROME-III

\section{Introduction}

Functional constipation (FC) is the most common functional gastrointestinal disorder (FGID) in childhood, with a reported prevalence ranging from below $1 \%$ to up to $32 \%$, depending on the reference population and the definition used [1]. The longstanding nature of the

\section{${ }^{a}$ 2nd Department of Pediatrics, University of Athens, "P \& Ag. Kyriakou" Children's Hospital (Giorgos L. Chouliaras, Panagiotis Krepis); ${ }^{b}$ st Department of Pediatrics, University of Athens, "Aghia Sophia" Children's Hospital (Ilias Bouzios, Aglaia Zellos, George Chrousos, Eleftheria Roma-Giannikou), Athens, Greece \\ Conflict of Interest: None}

Correspondence to: Giorgos Chouliaras, 2nd Department of Pediatrics, University of Athens, "P. \& Ag. Kyriakou" Children's Hospital, Thivon \& Levadias St., 11527, Athens, Greece, e-mail: georgehouliaras@msn.com

Received 7 November 2020; accepted 9 February 2021; published online 3 April 2021

DOI: https://doi.org/10.20524/aog.2021.0626 condition has a significant psychological impact on the family and poses a substantial economic burden for health systems, accounting for up to $25 \%$ of visits to a pediatric gastroenterologist in the United States (US) and comprising one of the 10 most common problems encountered by general pediatricians [2]. A study in the US on the cost of FC concluded that constipated children's mean annual cost to the health system was 3 times greater compared to healthy control group (CG) [3].

Understanding the etiological basis is essential in order to apply preventive measures for such a common and costly condition. Several hypotheses have been proposed in relation to the etiology of pediatric FC, including genetics, behavior, intestinal microbiota, brain-gut axis, and diet. In most cases univariate analyses have been implemented, focusing on one parameter [4]. In this study we aimed to assess dietary habits in a large population of children diagnosed with FC according to the Rome III criteria and to evaluate differences compared to non-constipated controls, 
through a multivariate analysis taking into account several confounding factors.

\section{Patients and methods}

The current study was a subgroup analysis of a crosssectional, school-based study [5] carried out by the 1st Department of Pediatrics of the National and Kapodistrian University of Athens, Greece, between January and June 2014, after receiving ethical approval by the Ethics Committee of the Ministry of Education (approval reference Id:305/25-05-2012). Written informed consent was sought and was signed by the parents or legal guardians of all participating children.

The methodological procedures have been described in detail previously [5]. In short, parents of children from schools (primary schools: 6-11-year-olds, gymnasiums: 12-14-year-olds, and lyceums: 15-17-year-olds) across the country were invited to participate via a letter and those consenting were included in the analysis. Two groups were formed: children with FC and CG. Children fulfilling the criteria for other FGIDs were excluded. The study sample was a sub-population of a national study on the prevalence of FGIDs in Greek children. Therefore, no samplesize calculation was applied for the present analysis, but all eligible children were included. Demographic, socioeconomic, clinical and dietary data were provided by the parents of children younger than 12 years, or directly by older children.

\section{Rome III questionnaire}

The official Greek translation of the Rome III questionnaire (QPGS-RIII) was utilized.

\section{Demographic/socioeconomic information}

The following data were recorded: geographic data (urban/ rural, mainland/islands, main urban centers/elsewhere); sex; age; parental country of origin (both parents Greek, one parent Greek and both parents non-Greek); paternal and maternal educational level (primary school, gymnasium, lyceum, higher degree); family's economic status (poor, average, good); number of adults at home; number of children at home; family size (2-3 persons, 4-5 persons, 6-8 persons); parental presence at home (single-parent families or not); TV exposure ( $\leq 1 \mathrm{~h}$ per day, 1-3 h per day, $>3 \mathrm{~h}$ per day); victim of bullying at school (yes/no); presence of a person with a severe health problem at home (yes/no); and level of physical exercise (none, 1-3 days per week, 4-7 days per week). For simplicity, paternal and maternal educational level (primary school $=0$, gymnasium $=1$, lyceum $=2$, higher degree $=3$ ) were combined (by aggregating the respective scores) to form a new variable, the combined parental educational level, which ranged from 0-6 and was treated as continuous for the purposes of the analysis

\section{Dietary information}

The questionnaire used in this study is a modified version of a frequency-based questionnaire of dietary habits published previously [6]. Details on the structure and administration of the final form of the questionnaire have been published before from our group in a study assessing dietary habits in abdominal pain-related functional gastrointestinal disorders [7]. In brief, the dietary parameters of interest in the present analysis were: dairy, meat, fish, fiber, junk food, and non-lactose simple carbohydrates. The following information was requested from the participants: occasions of fruit consumption per week (in any form); servings of fresh juice per week; fizzy drinks (cups or cans) per week; occasions of sweet consumption per week; occasions of savory snack consumption per week; servings of milk per week; occasions of cheese consumption per week; servings of yoghurt per week; of the 14 meals per week how many include vegetables/ legumes; of the 14 meals per week how many include salad; of the 14 meals per week how many include meat; of the 14 meals per week how many include fish; of the 14 meals per week how many include fast food, exclusively; in how many of the 14 meals per week is additional fast food consumed after the meal.

Dietary variables were organized into the following groups: fiber includes fruits, vegetables and salads; dairy includes milk, cheese and yoghurt; meat includes consumption of red or white meat; fish includes servings of any fish; junk food includes fast food and savory snacks; and non-lactose simple carbohydrates include fruits, juice, sweets and fizzy drinks. In all cases, frequencies and not actual quantities were assessed. A detailed description of the questionnaire and grouping of variables is provided in Table 1 .

\section{Statistical analysis}

Continuous data are presented using mean \pm standard deviation (SD) and median (interquartile range), while categorical variables are described using absolute (n) and relative (\%) frequencies. Continuous parameters were compared using the Student's $t$-test or the Mann-Whitney $U$ test in the case of skewed distributions. The relations between categorical variables were assessed using Fisher's exact test. In 2 previous studies in the same population [5,7], we showed that the socioeconomic and demographic background is related to the likelihood of any FGID, as well as abdominal pain-related FGID. In the present analysis, we initially used a stepwise logistic regression approach, incorporating all socioeconomic and demographic variables, to identify probable confounders. The statistically significant parameters derived from the first model were used as confounders in the second multivariate regression analysis, where we assessed the correlation of dietary habits with the likelihood of FC, which was the main aim of this study. Again, a stepwise, backwards procedure was applied, starting from the full model. For logistic regression analysis, results are reported as odds ratios (OR) and 95\% confidence 
intervals $(95 \% \mathrm{CI})$. The cutoff point for establishing statistical significance was set at $\mathrm{P}=0.05$. The analysis was carried out using Stata 11.0 MP software (StataCorp, TX).

Table 1 Food-frequency questionnaire and grouping of data

\begin{tabular}{|c|c|}
\hline Question & Group \\
\hline $\begin{array}{l}\text { Occasions of fruit consumption per } \\
\text { week (in any form) }\end{array}$ & $\begin{array}{l}\text { Fiber, non-lactose } \\
\text { simple carbohydrates }\end{array}$ \\
\hline Servings of fresh juice per week & $\begin{array}{l}\text { Non-lactose simple } \\
\text { carbohydrates }\end{array}$ \\
\hline Fizzy drinks (cups or cans) per week & $\begin{array}{l}\text { Non-lactose simple } \\
\text { carbohydrates }\end{array}$ \\
\hline $\begin{array}{l}\text { Occasions of sweet consumption per } \\
\text { week }\end{array}$ & $\begin{array}{l}\text { Non-lactose simple } \\
\text { carbohydrates }\end{array}$ \\
\hline $\begin{array}{l}\text { Occasions of savory }{ }^{\mathrm{a}} \text { snack } \\
\text { consumption per week }\end{array}$ & Junk food \\
\hline Servings of milk per week & Dairy \\
\hline $\begin{array}{l}\text { Occasions of cheese consumption per } \\
\text { week }\end{array}$ & Dairy \\
\hline Servings of yoghurt per week & Dairy \\
\hline $\begin{array}{l}\text { Out of the } 14 \text { meals per week, how } \\
\text { many include vegetables/legumes? }\end{array}$ & Fiber \\
\hline $\begin{array}{l}\text { Out of the } 14 \text { meals per week, how } \\
\text { many include salad? }\end{array}$ & Fiber \\
\hline $\begin{array}{l}\text { Out of the } 14 \text { meals per week, how } \\
\text { many include meat?b }\end{array}$ & Meat \\
\hline $\begin{array}{l}\text { Out of the } 14 \text { meals per week, how } \\
\text { many include fish? }\end{array}$ & Fish \\
\hline $\begin{array}{l}\text { Out of the } 14 \text { meals per week, how } \\
\text { many include fast food', exclusively? }\end{array}$ & Junk food \\
\hline $\begin{array}{l}\text { In how many of the } 14 \text { meals per week } \\
\text { is additional fast food }{ }^{\circ} \text { consumed after } \\
\text { the meal? }\end{array}$ & Junk food \\
\hline
\end{tabular}

\section{Results}

\section{Associations of FC with socioeconomic and demographic characteristics}

Two thousand five hundred questionnaires were distributed, and informed consent was not provided for 842 children $(33.7 \%$ negative response). Of the remaining 1658 children, complete dietary data were available for 1439 (1218 CG, 221 FC). Participants with missing dietary data were not included in the analysis. Age and sex were comparable between the 2 groups (age, FC vs. CG: $13.0 \pm 2.7$ vs. $12.8 \pm 2.8, \mathrm{P}=0.27$; sex, females, FC vs. CG: $50.7 \%$ vs. $50.2 \%, \mathrm{P}=0.94$ ). Detailed demographic and socioeconomic data are presented in Tables 2 and 3, respectively, along with bivariate associations with FC.

When a multiple, backwards, stepwise, logistic regression analysis was applied, starting from a full model with all socioeconomic and demographic data, the following parameters were significant in the final equation: physical activity (4-7 days per week vs. none, OR 0.53 , 95\%CI 0.36 $0.77, \mathrm{P}=0.001$ ), bullying (yes vs. no, OR $1.69,95 \% \mathrm{CI} 1.08-2.65$, $\mathrm{P}=0.022$ ), TV exposure ( $>3 \mathrm{~h}$ per day vs. $\leq 1 \mathrm{~h}$, OR $1.88,95 \% \mathrm{CI}$ 1.11-3.18, $\mathrm{P}=0.019$ ), parental educational level (OR 0.87, 95\%CI 0.78-0.95, $\mathrm{P}=0.005$ ), area of residence (main urban centers Athens/Thessaloniki vs. elsewhere, OR 0.66, 95\%CI $0.48-0.91, \mathrm{P}=0.011$ ), and number of adults at home (4 vs. 2 , OR 2.42 , 95\%CI 1.37-4.30, $\mathrm{P}=0.002$ ).

\section{Associations of FC with dietary habits}

Table 4 illustrates the associations between dietary parameters and the likelihood of FC. In this unadjusted, bivariate analysis, significant associations with FC were found for fiber, non-lactose simple carbohydrates and junk food.

Finally, a second multiple, backwards, stepwise, logistic regression analysis on the probability of FC was performed. We started from a full model including all dietary variables and the set of significant socioeconomic/demographic parameters

Table 2 Demographic factors in the study population and associations with FC

\begin{tabular}{lccc}
\hline Demographic characteristic, $n(\%)$ & Total $(\mathrm{n}=1439)$ & FC (n=221) & Controls (n=1218) \\
\hline Group & $377(26.2 \%)$ & $53(24.0 \%)$ & $324(26.6 \%)$ \\
$\quad$ Primary school (6-12 years) & $1062(73.8 \%)$ & $168(76.0 \%)$ & $894(73.4 \%)$ \\
$\quad$ High school (gymnasium \& lyceum, 12-18 years) & & & 0.455 \\
Main urban centers & $788(54.8 \%)$ & $96(43.4 \%)$ & $692(56.9 \%)$ \\
$\quad$ Athens \& Thessaloniki & $650(45.2 \%)$ & $125(56.6 \%)$ & $525(43.1 \%)$ \\
$\quad$ Elsewhere & & & $369(30.3 \%)$ \\
Urban vs. rural & $459(31.9 \%)$ & $90(40.7)$ & $848(69.7 \%)$ \\
$\quad$ Rural & $979(68.1 \%)$ & $131(59.3 \%)$ & 0.003 \\
$\quad$ Urban & $1190(82.7 \%)$ & $168(76.0 \%)$ & $1022(84.0 \%)$ \\
Islands vs. mainland Greece & $248(17.3 \%)$ & $53(24.0 \%)$ & $195(16.0 \%)$ \\
$\quad$ Mainland Greece & & & 0.005 \\
$\quad$ Islands & &
\end{tabular}

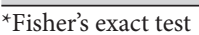

FC, functional constipation 
Table 3 Socioeconomic factors [3 (A) categorical variables, 3 (B) continuous variables] in the study population and associations with FC

\begin{tabular}{|c|c|c|c|c|}
\hline $3(\mathrm{~A})$ & Total $(\mathrm{n}=1439)$ & $\mathrm{FC}^{\mathrm{a}}(\mathrm{n}=221)$ & Controls $(\mathrm{n}=1218)$ & P-value ${ }^{*}$ \\
\hline $\begin{array}{l}\text { Paternal educational level } \\
\text { Primary school } \\
\text { Gymnasium } \\
\text { Lyceum } \\
\text { University }\end{array}$ & $\begin{array}{c}69(4.8 \%) \\
219(15.2 \%) \\
565(39.3 \%) \\
585(40.7 \%)\end{array}$ & $\begin{array}{c}17(7.7 \%) \\
47(21.3 \%) \\
92(41.6 \%) \\
65(29.4 \%)\end{array}$ & $\begin{array}{c}52(4.3 \%) \\
172(14.1 \%) \\
473(38.9 \%) \\
520(42.7 \%)\end{array}$ & $<0.001$ \\
\hline $\begin{array}{l}\text { Maternal educational level } \\
\text { Primary school } \\
\text { Gymnasium } \\
\text { Lyceum } \\
\text { University }\end{array}$ & $\begin{array}{c}69(4.8 \%) \\
118(8.2 \%) \\
585(40.7 \%) \\
666(46.3 \%)\end{array}$ & $\begin{array}{l}17(7.7 \%) \\
31(14.0 \%) \\
92(41.6 \%) \\
81(36.7 \%)\end{array}$ & $\begin{array}{c}52(4.3 \%) \\
87(7.1 \%) \\
493(40.5 \%) \\
585(48.1 \%)\end{array}$ & $<0.001$ \\
\hline $\begin{array}{l}\text { Family's economic status } \\
\text { Good } \\
\text { Average } \\
\text { Poor }\end{array}$ & $\begin{array}{l}553(38.4 \%) \\
803(55.8 \%) \\
83(5.8 \%)\end{array}$ & $\begin{array}{c}83(37.6 \%) \\
123(55.7 \%) \\
15(6.8 \%)\end{array}$ & $\begin{array}{l}470(38.6 \%) \\
680(55.8 \%) \\
68(5.6 \%)\end{array}$ & 0.749 \\
\hline $\begin{array}{l}\text { Number of adults at home } \\
1 \\
2 \\
3 \\
4\end{array}$ & $\begin{array}{c}95(6.6 \%) \\
1171(81.4 \%) \\
110(7.6 \%) \\
60(4.2 \%)\end{array}$ & $\begin{array}{c}18(8.1 \%) \\
164(74.2 \%) \\
18(8.1 \%) \\
21(9.6 \%)\end{array}$ & $\begin{array}{c}77(6.3 \%) \\
1007(82.7 \%) \\
92(7.6 \%) \\
42(3.4 \%)\end{array}$ & 0.001 \\
\hline $\begin{array}{l}\text { Family size (persons at home) } \\
2-3 \text { persons } \\
4-5 \text { persons } \\
6-8 \text { persons }\end{array}$ & $\begin{array}{c}243(16.9 \%) \\
1021(71.0 \%) \\
174(12.1 \%)\end{array}$ & $\begin{array}{c}40(18.1 \%) \\
139(62.9 \%) \\
42(19.0 \%)\end{array}$ & $\begin{array}{l}203(16.7 \%) \\
882(72.5 \%) \\
132(10.9 \%)\end{array}$ & 0.002 \\
\hline $\begin{array}{l}\text { Parental presence at home } \\
\text { Single parent } \\
\text { Both parents }\end{array}$ & $\begin{array}{c}120(8.3 \%) \\
1319(91.7 \%)\end{array}$ & $\begin{array}{c}21(9.5 \%) \\
200(90.5 \%)\end{array}$ & $\begin{array}{c}99(8.1 \%) \\
1119(91.9 \%)\end{array}$ & 0.508 \\
\hline $\begin{array}{l}\text { Days of physical exercise per week } \\
\text { None } \\
\text { 1-3 days } \\
4-7 \text { days }\end{array}$ & $\begin{array}{l}236(16.4 \%) \\
807(56.1 \%) \\
395(27.5)\end{array}$ & $\begin{array}{c}42(19.0 \%) \\
139(62.9 \%) \\
40(18.1 \%)\end{array}$ & $\begin{array}{l}194(15.9 \%) \\
668(54.9 \%) \\
355(29.2 \%)\end{array}$ & 0.002 \\
\hline $\begin{array}{l}\text { Television exposure (h per day) } \\
\leq 1 \\
1-3 \\
>3\end{array}$ & $\begin{array}{c}525(36.5 \%) \\
835(58.0 \%) \\
79(5.5 \%)\end{array}$ & $\begin{array}{c}60(27.2 \%) \\
138(62.4 \%) \\
23(10.4 \%)\end{array}$ & $\begin{array}{l}465(38.2 \%) \\
697(57.2 \%) \\
56(4.6 \%)\end{array}$ & $<0.001$ \\
\hline $\begin{array}{l}\text { Victim of "bullying" at school } \\
\text { No } \\
\text { Yes }\end{array}$ & $\begin{array}{c}1300(90.3 \%) \\
139(9.7 \%)\end{array}$ & $\begin{array}{c}190(86.0 \%) \\
31(14.0 \%)\end{array}$ & $\begin{array}{c}1110(91.1 \%) \\
108(8.9 \%)\end{array}$ & 0.025 \\
\hline $\begin{array}{l}\text { Person at home with a severe health problem } \\
\text { No } \\
\text { Yes }\end{array}$ & $\begin{array}{c}1340(93.1 \%) \\
99(6.9 \%)\end{array}$ & $\begin{array}{c}200(90.5 \%) \\
21(9.5 \%)\end{array}$ & $\begin{array}{l}1140(93.6 \%) \\
78(6.4 \%)\end{array}$ & 0.111 \\
\hline \multicolumn{5}{|l|}{$3(\mathrm{~B})$} \\
\hline Variable & $\begin{array}{l}\text { Total }(\mathrm{n}=1439) \\
\text { mean } \pm \mathrm{SD} \\
\text { median }(\mathrm{IQR})\end{array}$ & $\begin{array}{l}\mathrm{FC}(\mathrm{n}=221) \\
\text { mean } \pm \text { SD, } \\
\text { median (IQR) }\end{array}$ & $\begin{array}{l}\text { Controls }(\mathrm{n}=1218) \\
\text { mean } \pm \mathrm{SD} \\
\text { median }(\mathrm{IQR})\end{array}$ & P-value ${ }^{* *}$ \\
\hline Number of children at home & $2.2 \pm 0.9,2(2,3)$ & $2.4 \pm 1.0,2(2,3)$ & $2.2 \pm 0.9,2(2,2)$ & 0.015 \\
\hline Parental combined educational level & $4.4 \pm 1.5,5(4,6)$ & $4.0 \pm 1.6,4(3,5)$ & $4.5 \pm 1.4,5(4,6)$ & $<0.001$ \\
\hline $\begin{array}{l}{ }^{*} \text { Fisher's exact test } \\
{ }^{*} \text { Mann-Whitney test }\end{array}$ & & & & \\
\hline $\begin{array}{l}\text { The parental combined educational level is a } 0-6 \mathrm{sc} \\
\text { lyceum: } 2 \text {, higher degree: } 3\end{array}$ & ing from summin & rnal and paterna & nal level: primary sc & nnasium: 1, \\
\hline
\end{tabular}

that resulted from the first model. In the final, reduced model, parental educational level, victimization, physical activity and number of adults at home retained their statistical significance.
In relation to dietary variables only fiber was statistically significant. Consumption of fiber had an inverse relation to the likelihood of FC (OR 0.98, 95\%CI 0.96-0.99, $\mathrm{P}=0.048$ ). 
Table 4 Distribution of dietary parameters in the study population and comparisons between children with FC and controls

\begin{tabular}{lcccc}
\hline Dietary variable & $\begin{array}{c}\text { Total } \\
\text { mean } \pm \mathrm{SD}^{\mathrm{d}}, \\
\text { median }\left(\mathrm{IQR}^{\mathrm{e}}\right)\end{array}$ & $\begin{array}{c}\mathrm{FC} \\
\text { mean } \pm \mathrm{SD}^{\mathrm{d}}, \\
\text { median }\left(\mathrm{IQR}^{\mathrm{e}}\right)\end{array}$ & $\begin{array}{c}\text { Controls } \\
\text { mean } \pm \mathrm{SD}^{\mathrm{d}}, \\
\text { median }\left(\mathrm{IQR}^{\mathrm{e}}\right)\end{array}$ \\
\hline Fiber & $18.1 \pm 9.1,17(11,24)$ & $16.5 \pm 9.0,15(10,22)$ & $18.4 \pm 9.1,17(11,24)$ & 0.005 \\
Dairy & $16.5 \pm 8.0,16(11,21)$ & $15.9 \pm 10.1,15(10,20)$ & $16.5 \pm 7.5,16(11,21)$ & 0.30 \\
Non-lactose simple carbohydrates & $13.5 \pm 7.6,15(11,21)$ & $15.2 \pm 8.9,13(10,18)$ & $13.1 \pm 7.3,12(8,16)$ & 0.001 \\
Junk food & $8.1 \pm 5.6,7(5,10)$ & $9.5 \pm 5.9,8(6,12)$ & $7.8 \pm 5.5,7(4,10)$ & $<0.001$ \\
Meat & $5.0 \pm 2.7,4(3,6)$ & $5.2 \pm 3.1,4(3,7)$ & $5.0 \pm 2.7,4(3,6)$ & 0.30 \\
Fish & $2.0 \pm 1.8,2(1,2)$ & $2.1 \pm 2.1,2(1,3)$ & $2.0 \pm 1.7,2(1,2)$ & 0.55 \\
\hline
\end{tabular}

${ }^{\star}$ Servings per week. $†$ Student's t-test

$F C$, functional constipation; SD, standard deviation; IQR, interquartile range

Twenty-seven children with FC also fulfilled the criteria for an abdominal-pain related FGID. In a previous study [7] we have shown that abdominal-pain related FGIDs are significantly associated with junk food and fish consumption. In order to detect whether the coexistence of abdominal painrelated FGIDs would confound the observed associations, the multivariate logistic regression analysis was repeated including only the 194 children with FC and without a diagnosis of abdominal pain-related FGIDs. The results remained practically unchanged regarding the direction of the estimated correlations.

\section{Discussion}

In the present study, we assessed the relation between dietary habits and the likelihood of FC in a large, school-based sample of Greek children, based on the Rome III criteria. We observed that a lower intake of fiber was the sole factor associated with a higher probability of FC, irrespective of socioeconomic and demographic background, which have been shown to correlate significantly with FGIDs.

In general, most of the hypothesized mechanisms in pediatric FC involve, as the final step, a withholding behavior attributed to underlying, longstanding fear of a painful defecation. This is triggered by hard, occasionally bulky, dehydrated stools, and repetitive postponement perpetuates a vicious cycle of pain, fear and avoidance. Different theories exist regarding what might systematically lead to this sequence of events. Prolonged colonic transit time, dietary factors (primarily low residue), changes in intestinal microbiota, even genetic predisposition have been implicated [2].

A uniformly accepted definition for fiber does not exist, and various different methods of characterization have been used. In all cases, the common denominator is that "dietary fiber is a group of carbohydrate polymers, oligomers and lignin that escape digestion in the small intestine and reach the colon intact, where they are partially or completely fermented by the gut microbiota" $[8,9]$. Fiber is probably the most extensively investigated dietary factor in pediatric and adult FC. In general, most observational studies have shown an inverse relation between consumption of fiber and likelihood of constipation, similar to our results. Depending on the design of each study, fiber intake may have been assessed either indirectly (through food frequency questionnaires, as consumption of fiber-containing foods) [10-12], or directly, after quantification through a 24- or 72-h dietary record form [13-15]. Furthermore, it has been shown that adhesion to dietary patterns rich in vegetables/fruits/whole-wheat grains, such as the Mediterranean diet, is inversely related to FGIDs and specifically FC in Greek children [16]. Based on observational results, clinical trials have been conducted in constipated children, aiming to assess fiber as a possible treatment. Several meta-analyses [17-19] have tried to summarize the results of the clinical trials. The most recent [20], which included all available data, concluded that fiber may be beneficial in improving evacuation frequency. All systematic reviews acknowledge the significant heterogeneity of the included trials in terms of constipation definition, method/dose/type of fiber supplementation and outcomes of interest. A 2014 decision analysis article [21] assessed the financial impact of increased fiber consumption and the subsequent reduction in the prevalence of constipation and related utilization of health resources. The estimated annual reduction in constipationrelated cost in the entire US adult population, would exceed 2 billion dollars if $50 \%$ of the US adult population reached the recommended daily consumption of fiber.

The beneficial effect of fiber in FC has been attributed to 2 factors. First, fiber, particularly low-fermentable and nonfermentable, acts as a bulking agent by increasing luminal water content [22]. Hydrated, bulky, soft stools promote normal motility of the colon [23] and reduce the probability of a painful, unpleasant feeling during the defecation by the young child, therefore preventing a withholding behavior. Second, in recent years, dietary fiber has been recognized as a major modifying factor of the gut microbiome. Modern modalities such as next-generation sequencing demonstrated intestinal dysbiosis in constipated adults [24,25]. Most data have shown an altered balance, with reduced presence of Bifidobacterium and Lactobacillus genera and increased abundance of Bacteroidetes and Enterobacteriaceae [26,27]. In pediatric populations similar studies are scarce. In otherwise healthy children with FC, 2 studies $[28,29]$ found significant increases 
in clostridia and bifidobacteria in FC, whereas another study in obese children with FC [30] demonstrated significantly smaller Prevotella populations and larger numbers of several genera of firmicutes.

It is mainly experimental data from animal studies that have provided insight into the physiological link between intestinal microbiota and FC. Current evidence suggests that a microbiome imbalance results in dysregulation of intestinal physiology in many aspects, including sensory, motor, immune and vascular functions [22]. A characteristic finding is that the bacterial endotoxin lipopolysaccharide is able to influence intestinal motility by prolonging gastric emptying time and causing sphincter dysfunction [31]. The short chain fatty acids (SCFAs) produced by some gut microbes induce the release of GLP-1 and polypeptide YY and stimulate the enteric cholinergic reflex [32,33]. A different mode of action for SCFAs includes the induction of 5-hydroxytryptamine release, thus accelerating colonic transit [34]. It is evident that gut microbiota have multiple potential roles in intestinal health through complex physiologic mechanisms at the cellular and molecular level, which remain largely unknown.

There is no universally endorsed recommendation of daily fiber intake for children. A widely used "rule of thumb" is the age (in years) plus 5-10 g [35]. A prospective study in constipated children identified that at least $10 \mathrm{~g}$ of daily dietary fiber for younger children (3-7 years) and at least $15 \mathrm{~g}$ of daily dietary fiber for older children (8-14 years) are the recommended cutoffs to relieve constipation [36]. The most recent (2014) guidelines of the European and North American Societies of Pediatric, Gastroenterology Hepatology and Nutrition do not recommend extra fiber supplementation in children with FC [37].

The main strength of this study is its large sample size, which provided increased power to detect statistically significant associations via multivariate models that effectively eliminated the confounding effect of socioeconomic variables. The main limitation was the cross-sectional nature of the survey and the use of Rome III (instead of the currently available Rome IV) criteria. When the present study was being conducted the Rome IV version was not yet available. Studies comparing the performance of Rome III vs. Rome IV have shown relatively good agreement, despite the changes in the FC criteria [38]. In addition, the study could be subject to response bias; a social desirability effect may have shaped participants' answers. Moreover, participants' dietary habits were not interpreted in the form of total caloric intake or a summary of consumed food quantities, and no grouping of children based on their exact nutritional intake was performed. The use of weighed food diaries, instead of food frequency questionnaires, would have provide information on whether the upper limits of recommended daily allowances for dairy products were exceeded or those for fiber intake were not reached in children with FC.

In conclusion, the present study demonstrated a significant association between fiber and the likelihood of FC in schoolaged children, independently of socioeconomic background. The amount and type of fiber that provide the maximum beneficial effect remain to be determined in future studies.

\section{Acknowledgment}

The authors would like to thank Christina Kondyli (Clinical Dietician) for her valuable contribution in processing and finalizing the dietary questionnaire

\section{Summary Box}

\section{What is already known:}

- Functional constipation (FC) is a common condition of unknown, multifactorial etiology

- Diet as a contributing factor has been investigated with inconclusive results

- Diet-related prevention strategies are not feasible because of the lack of specific aims

\section{What the new findings are:}

- Fiber-containing food, when assessed simultaneously with other dietary parameters, is the sole factor associated with FC

- Dietary habits should be assessed in the context of socioeconomic and lifestyle risk factors, such as physical activity, bullying, parental educational level and number of adults at home, which are significantly and independently associated with a higher likelihood of FC

\section{References}

1. Koppen IJN, Vriesman MH, Saps M, et al. Prevalence of functional defecation disorders in children: a systematic review and metaanalysis. J Pediatr 2018;198:121-130.

2. Koppen IJ, Lammers LA, Benninga MA, Tabbers MM. Management of functional constipation in children: therapy in practice. Paediatr Drugs 2015;17:349-360.

3. Park R, Mikami S, LeClair J, et al. Inpatient burden of childhood functional GI disorders in the USA: an analysis of national trends in the USA from 1997 to 2009. Neurogastroenterol Motil 2015;27:684-692.

4. Vriesman MH, Koppen IJN, Camilleri M, Di Lorenzo C, Benninga MA. Management of functional constipation in children and adults. Nat Rev Gastroenterol Hepatol 2020;17:21-39.

5. Bouzios I, Chouliaras G, Chrousos GP, Roma E, GemouEngesaeth V. Functional gastrointestinal disorders in Greek children based on ROME III criteria: identifying the child at risk. Neurogastroenterol Motil 2017;29.

6. Turconi G, Celsa M, Rezzani C, Biino G, Sartirana MA, Roggi C. Reliability of a dietary questionnaire on food habits, eating behaviour and nutritional knowledge of adolescents. Eur J Clin Nutr 2003;57:753-763.

7. Chouliaras G, Kondyli C, Bouzios I, Spyropoulos N, Chrousos GP, Roma-Giannikou E. Dietary habits and abdominal painrelated functional gastrointestinal disorders: a school-based, cross-sectional analysis in Greek children and adolescents. 
J Neurogastroenterol Motil 2019;25:113-122.

8. Wegh CAM, Schoterman MHC, Vaughan EE, Belzer C, Benninga MA. The effect of fiber and prebiotics on children's gastrointestinal disorders and microbiome. Expert Rev Gastroenterol Hepatol 2017;11:1031-1045.

9. Fuller S, Beck E, Salman H, Tapsell L. New horizons for the study of dietary fiber and health: a review. Plant Foods Hum Nutr 2016;71:1-12.

10. Tam YH, Li AM, So HK, et al. Socioenvironmental factors associated with constipation in Hong Kong children and Rome III criteria. J Pediatr Gastroenterol Nutr 2012;55:56-61.

11. Sujatha B, Velayutham DR, Deivamani N, Bavanandam S. Normal bowel pattern in children and dietary and other precipitating factors in functional constipation. J Clin Diagn Res 2015;9:SC12-SC15.

12. Andreoli CS, Vieira-Ribeiro SA, Fonseca PCA, et al. Eating habits, lifestyle and intestinal constipation in children aged four to seven years. Nutr Hosp 2019;36:25-31.

13. Ip KS, Lee WT, Chan JS, Young BW. A community-based study of the prevalence of constipation in young children and the role of dietary fibre. Hong Kong Med J 2005;11:431-436.

14. Morais MB, Vítolo MR, Aguirre AN, Fagundes-Neto U. Measurement of low dietary fiber intake as a risk factor for chronic constipation in children. J Pediatr Gastroenterol Nutr 1999;29:132-135.

15. Roma E, Adamidis D, Nikolara R, Constantopoulos A, Messaritakis J. Diet and chronic constipation in children: the role of fiber. J Pediatr Gastroenterol Nutr 1999;28:169-174.

16. Agakidis C, Kotzakioulafi E, Petridis D, Apostolidou K, Karagiozoglou-Lampoudi T. Mediterranean diet adherence is associated with lower prevalence of functional gastrointestinal disorders in children and adolescents. Nutrients 2019;11:1283.

17. Yang J, Wang HP, Zhou L, Xu CF. Effect of dietary fiber on constipation: a meta analysis. World J Gastroenterol 2012;18:7378-7383.

18. Han Y, Zhang L, Liu XQ, Zhao ZJ, Lv LX. Effect of glucomannan on functional constipation in children: a systematic review and meta-analysis of randomised controlled trials. Asia Pac J Clin Nutr 2017;26:471-477.

19. Gordon M, Naidoo K, Akobeng AK, Thomas AG. Cochrane Review: Osmotic and stimulant laxatives for the management of childhood constipation (Review). Evid Based Child Health 2013;8:57-109.

20. Piccoli de Mello P, Eifer DA, Daniel de Mello E. Use of fibers in childhood constipation treatment: systematic review with metaanalysis. J Pediatr (Rio J) 2018;94:460-470.

21. Schmier JK, Miller PE, Levine JA, et al. Cost savings of reduced constipation rates attributed to increased dietary fiber intakes: a decision-analytic model. BMC Public Health 2014;14:374.

22. Ceresola ER, Ferrarese R, Preti A, Canducci F. Targeting patients' microbiota with probiotics and natural fibers in adults and children with constipation. Eur Rev Med Pharmacol Sci 2018;22:7045-7057.

23. Eswaran S, Muir J, Chey WD. Fiber and functional gastrointestinal disorders. Am J Gastroenterol 2013;108:718-727.

24. Simrén M, Barbara G, Flint HJ, et al; Rome Foundation Committee. Intestinal microbiota in functional bowel disorders: a Rome foundation report. Gut 2013;62:159-176.

25. Ohman L, Simren M. Intestinal microbiota and its role in irritable bowel syndrome (IBS). Curr Gastroenterol Rep 2013;15:323.

26. Khalif IL, Quigley EM, Konovitch EA, Maximova ID. Alterations in the colonic flora and intestinal permeability and evidence of immune activation in chronic constipation. Dig Liver Dis 2005;37:838-849.

27. Zhao Y, Yu YB. Intestinal microbiota and chronic constipation. Springerplus 2016;5:1130.

28. de Meij TG, de Groot EF, Eck A, et al. Characterization of microbiota in children with chronic functional constipation. PLoS One 2016;11:e164731.

29. Zoppi G, Cinquetti M, Luciano A, Benini A, Muner A, Bertazzoni Minelli E. The intestinal ecosystem in chronic functional constipation. Acta Paediatr 1998;87:836-841.

30. Zhu L, Liu W, Alkhouri R, et al. Structural changes in the gut microbiome of constipated patients. Physiol Genomics 2014;46:679-686.

31. Fan YP, Chakder S, Gao F, Rattan S. Inducible and neuronal nitric oxide synthase involvement in lipopolysaccharide-induced sphincteric dysfunction. Am J Physiol Gastrointest Liver Physiol 2001;280:G32-G42.

32. Wong JM, de Souza R, Kendall CW, Emam A, Jenkins DJ. Colonic health: fermentation and short chain fatty acids. J Clin Gastroenterol 2006;40:235-243.

33. Barbara G, Stanghellini V, Brandi G, et al. Interactions between commensal bacteria and gut sensorimotor function in health and disease. Am J Gastroenterol 2005;100:2560-2568.

34. Jennings A, Davies GJ, Costarelli V, Dettmar PW. Dietary fibre, fluids and physical activity in relation to constipation symptoms in pre-adolescent children. J Child Health Care 2009;13:116-127.

35. Kranz S, Brauchla M, Slavin JL, Miller KB. What do we know about dietary fiber intake in children and health? The effects of fiber intake on constipation, obesity, and diabetes in children. Adv Nutr 2012;3:47-53.

36. Chao HC, Lai MW, Kong MS, Chen SY, Chen CC, Chiu CH. Cutoff volume of dietary fiber to ameliorate constipation in children. J Pediatr 2008;153:45-49.

37. Tabbers MM, DiLorenzo C, Berger MY, et al; North American Society for Pediatric Gastroenterology. Evaluation and treatment of functional constipation in infants and children: evidence-based recommendations from ESPGHAN and NASPGHAN. J Pediatr Gastroenterol Nutr 2014;58:258-274.

38. Russo M, Strisciuglio C, Scarpato E, Bruzzese D, Casertano M, Staiano A. Functional chronic constipation: Rome III criteria versus Rome IV criteria. J Neurogastroenterol Motil 2019;25:123-128. 